\title{
Role of autonomic nervous system in chronic complete heart block
}

\author{
J. F. Finucane ${ }^{1}$ and John Gialafos ${ }^{2}$ \\ From St. George's Hospital, London
}

\begin{abstract}
Autonomic blockade was produced in 9 patients with chronic complete heart block by the intravenous administration of atropine and propranolol. Atrial and ventricular rates after injection were compared with those before. In general, the atrial rate slowed and there was no significant change in ventricular rate. However, 2 patients with an initial ventricular rate of over 40 a minute showed significant slowing. It is suggested that in chronic complete heart block the sinoatrial node is under dominant sympathetic control. High resting idioventricular rates may be partly dependent on sympathetic drive, but this does not appreciably influence resting idioventricular rate in the majority of cases.
\end{abstract}

The use of propranolol and atropine, given together, to produce autonomic blockade of the heart was first described by Jose (1966). He termed the resulting heart rate the 'intrinsic rate'. He found that this rate was relatively constant from the 4 th to the roth minute after administration of the drugs, and that it was also highly reproducible in successive studies on individual subjects (Jose and Collison, 1970). The findings were confirmed by some workers (Frick, Heikkila, and Kahanpaa, I967) but not by others (Conway, Fowler, and Bloom, I969). The intrinsic heart rate was found to be higher than the control rate in all cases except for a few patients who had severe heart disease. The increment in heart rate after blockade was inversely related to age.

Hirsch, Kaiser, and Cooper (1965) have demonstrated a rich nerve supply to the atrial and ventricular conducting tissue. Sympathetic stimulation increases the rate of inherent discharge in the atrioventricular node, whereas stimulation of the left vagus slows, and may completely block, atrioventricular nodal conduction (Davies, I97I).

We have studied the effect of autonomic blockade on the atrial and ventricular rates in patients with chronic complete heart block, to determine the role of the autonomic nervous system in this condition.

Received 28 March 1974.

${ }_{1}^{1}$ Present address: Department of Medicine, Queen Elizabeth Hospital, Birmingham Br 5 2TH.

2 Present address: Hippocratus Hospital Medical School, University of Athens, Ampelokipi, Athens.

\section{Patients and methods}

Informed consent was obtained from 9 volunteer patients ( 7 men, 2 women) of St. George's Hospital, who were being artificially paced for chronic complete heart block. Their ages ranged from 65 to 75 years (mean 70 years). The disease was first documented between 4 weeks and 9 years before the study. Each patient was paced via an endocardial pacing electrode attached to the external impulse generator. In each case idioventricular rhythm could be established when the pacing rate was slowed sufficiently and the impulse generator could then be switched off. No patient was pyrexial or in cardiac failure at the time of study. Two patients had suffered previous myocardial infarction; 3 had equivocal evidence of ischaemic heart disease and the remaining 4 had no associated cardiovascular disease. Two patients were being treated with digoxin and frusemide, one with frusemide only, and the remaining 6 were receiving no drug therapy. One patient was studied three times, 5 were studied twice, and single studies were carried out in 3 patients. Repeated studies were performed on successive days.

Patients were studied lying in bed, after at least one hour's bed rest. The rate before blockade (control rate) was determined from a I-minute continuous electrocardiogram tracing recorded 5 minutes after cessation of pacing, and establishment of idioventricular rhythm. The patient was then given, intravenously, atropine $0.04 \mathrm{mg} / \mathrm{kg}$ and propranolol $0.2 \mathrm{mg} / \mathrm{kg}$ mixed in the same syringe, over a 2-minute period. The electrocardiogram was continuously recorded from the end of the 2nd to the end of the I 5 th minute after completion of the injection. The atrial and ventricular rates from the 4 th to the roth minute were counted. Ventricular ectopics, where they occurred, were included. Blood pressure was measured immediately before, and 15 minutes after 
injection. The intrinsic rate was taken as the mean of the rates between the 4 th and roth minutes after completion of the injection.

\section{Results}

Results are summarized in the Table. Blockade caused a significant $(\mathbf{P}<0.0 \mathrm{r})$ slowing of the atrial rate in 14 out of 16 studies. In the majority of cases there was an associated but not significant $(P>0 \cdot I)$ slowing of ventricular rate. In two studies (Cases 4 and 5) where the control ventricular rates were 44 a minute, falls of 8 a minute and 6 a minute, respectively, were recorded. One patient, who was studied twice, showed small increases in both atrial and ventricular rates on both occasions.

The degree of atrial slowing was greatest in patients with high control rates. There was wide variation in the control atrial and ventricular rates both in different subjects, and also in the same subject on successive days. Rates over the period 4 to Io minutes after blockade were fairly constant (Fig.), but in cases where successive studies were carried out the reproducibility of the intrinsic rates was poor.

Eight out of 9 patients had an intrinsic atrial rate lower than predicted from the regression equation of Jose and Collison (1970).

TABLE

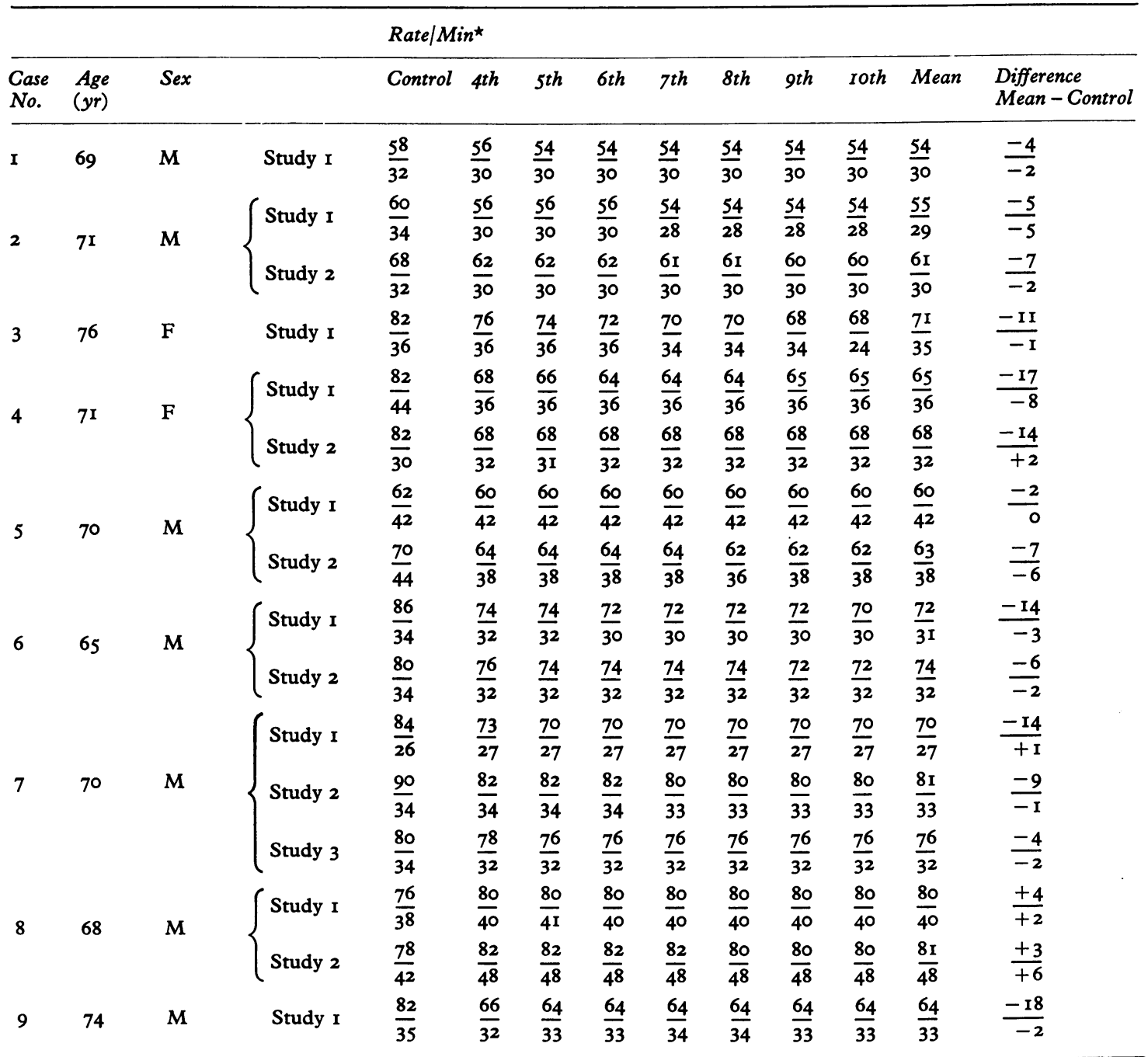

* In each study, upper figures refer to atrial rate and lower figures to ventricular rate. 


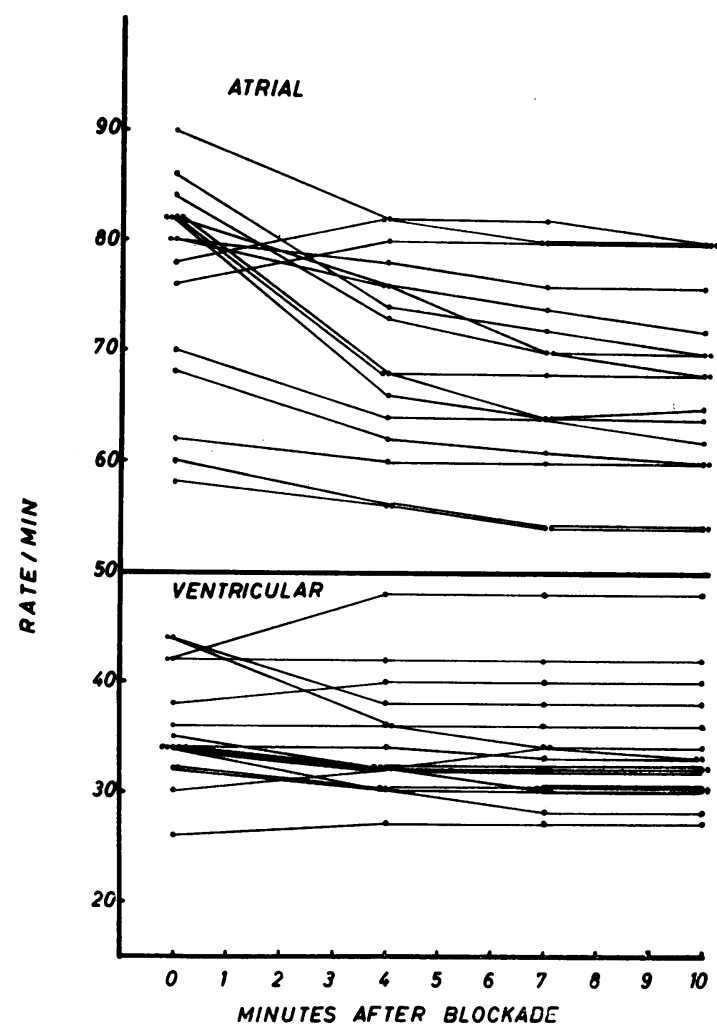

FIG.

Most patients showed a moderate fall in both systolic and diastolic blood pressure measured I5 minutes after injection. The maximum recorded fall was $40 \mathrm{mmHg}$ systolic and $30 \mathrm{mmHg}$ diastolic. No patient developed symptoms of hypotension, and blood pressure had returned to preblockade levels in all cases within one hour of completion of the study. Seven patients became somewhat confused between 30 and 90 minutes after injection, and were later able to recall unpleasant hallucinations. This effect was observed after the first study in 2 patients, and after a second successive daily study in 5 patients. No further studies were carried out in those circumstances.

\section{Discussion}

The slowing of atrial rate after autonomic blockade suggests a predominant sympathetic influence on the sinoatrial node. This has previously been described only in patients with severe and poorly compensated disease (ischaemic, valvular, etc.) (Jose, 1966). The patients studied by us were haemo- dynamically well compensated. The absence of significant change in ventricular rate suggests that the autonomic nervous system plays no significant part in determining resting idioventricular rate in the majority of patients with chronic complete heart block. The findings are also explicable in terms of equal sympathetic and parasympathetic influences on the AV node being abolished simultaneously. This seems to be a less likely explanation since it is difficult to envisage sympathetic predominance in the sinoatrial node without concurrent predominance on the atrioventricular node. However, the high resting idioventricular rates found in a minority of cases may be partially dependent on sympathetic drive.

Apart from the autonomic nervous system, other factors such as body temperature, exercise, and salicylate therapy affect intrinsic heart rate (Jose and Collison, 1970; Jose, Stitt, and Collison, 1970), hence the variable reproducibility of the test in the same individual (Frick et al., 1967). None of these factors operated in our patients. Presumably other unidentified influences can alter the inherent rhythmicity of the sinoatrial and atrioventricular nodes.

Intrinsic atrial rates were lower than predicted (Jose and Collison, 1970), and this may be a pointer to the coexistence of impaired sinoatrial function in chronic complete heart block.

We thank Dr. Aubrey Leatham and Dr. Alan Harris for advice and criticism.

\section{References}

Conway, N., Fowler, J. M., and Bloom, S. (1969). Heart rate after combined vagal and sympathetic blockade in patients with heart disease. British Heart fournal, 31, 591.

Davies, M. J. (1971). Pathology of Conducting Tissue of the Heart. Butterworth, London.

Frick, M. H., Heikkila, J., and Kahanpaa, A. (1967). Combined parasympathetic and beta-receptor blockade as a clinical test. Acta Medica Scandinavica, 182, 621.

Hirsch, E. F., Kaiser, G. C., and Cooper, T. (1965). Experimental heart block in the dog. Archives of Pathology, 79, $44 \mathrm{I}$.

Jose, A. D. (1966). Effect of combined sympathetic and parasympathetic blockade on heart rate and cardiac function in man. American fournal of Cardiology, 18, 476.

Jose, A. D., and Collison, D. (1970). The normal range and determinants of the intrinsic heart rate in man. Cardiovascular Research, 4, 160.

Jose, A. D., Stitt, F., and Collison, D. (1970). The effects of exercise and changes in body temperature on the intrinsic heart rate in man. American Heart fournal, 79, 488.

Requests for reprints to Dr. J. F. Finucane, Department of Medicine, Queen Elizabeth Hospital, Edgbaston, Birmingham Br5 2TH. 